\title{
The Global Study of Philanthropic Behavior
}

\author{
Pamala Wiepking ${ }^{1,2}$ [D
}

Accepted: 21 September 2020/Published online: 9 October 2020

(C) The Author(s) 2020

\begin{abstract}
While there is apparent evidence that individual philanthropic behavior and the motivations for this behavior are at least to some extent universal, there is also evidence that people across the world do not equally display this behavior. In this conceptual article, I explore how we can study philanthropic behaviors from a global perspective. I contend that the macro-level study of philanthropy is underdeveloped, because of three problems intrinsic to the study of global philanthropy: problems with geographical orientation, connotations and definitions. As a first step to overcome these problems, I suggest the use of the term generosity behavior over philanthropic behavior, as this term appears more inclusive of the multitude of definitions and connotations across cultures. I conclude by formulating a collaborative research agenda for a more inclusive study and understanding of global generosity behavior, focused on generating publicly accessible knowledge and informing policy.
\end{abstract}

Keywords Philanthropy · Generosity · Giving · Comparative study

Selections of this manuscript are based on Pamala Wiepking's keynote at the ninth conference of the European Research Network on Philanthropy, July 4, 2019, Basel, Switzerland.

Pamala Wiepking

pwiepki@iu.edu; p.wiepking@vu.nl

1 IU Lilly Family School of Philanthropy, Indianapolis University Hall Suite 3000, 301 University Blvd, Indianapolis, IN 46202-5146, USA

2 Center for Philanthropic Studies, Vrije Universiteit Amsterdam, De Boelelaan 1081, 1081 HV Amsterdam, The Netherlands
Across cultures, people display a wide range of philanthropic behaviors, including cooperating in public good games (Henrich et al. 2004), benefitting others through volunteering (Ruiter and De Graaf 2006), giving money (Borgonovi 2008) and helping strangers (Bennett and Einolf 2017). Research thus shows that philanthropic behavior is - at least to some extent-universal. Research across different disciplines also supports the idea that there is some universality in the individual motivations for this behavior. Aknin et al. (2013) show that people across cultures experience a "warm glow" of giving. This is supported by the recent meta-analyses of functional magnetic resonance imaging (fMRI) studies on altruistic and strategic decisions to give by Cutler and Campbell-Meiklejohn (2019): When contributing to others, areas in the brain related to reward processing light up. In another recent meta-analyses, Thielmann, Spadaro and Balliet (2020) show the influence of personality traits on prosocial behavior and conclude that traits related to the unconditional concern of others' welfare (such as social value orientation, altruism, concern for others and empathy) are more strongly correlated with prosocial behavior in economic games.

However, research also shows large variation across countries and cultures in different types of philanthropic behaviors. Take as an example the average amounts people donate to charitable causes across a range of nineteen countries, as displayed in Fig. 1.

The average amounts people donate to charitable causes range from 1427 US dollar in the USA to the equivalent of 12 US dollar in Russia. To take another measure, the percentage of people in a country helping a stranger, as displayed in Table 1.

Table 1 shows that there is large variation across countries in the percentage of people who report to have 


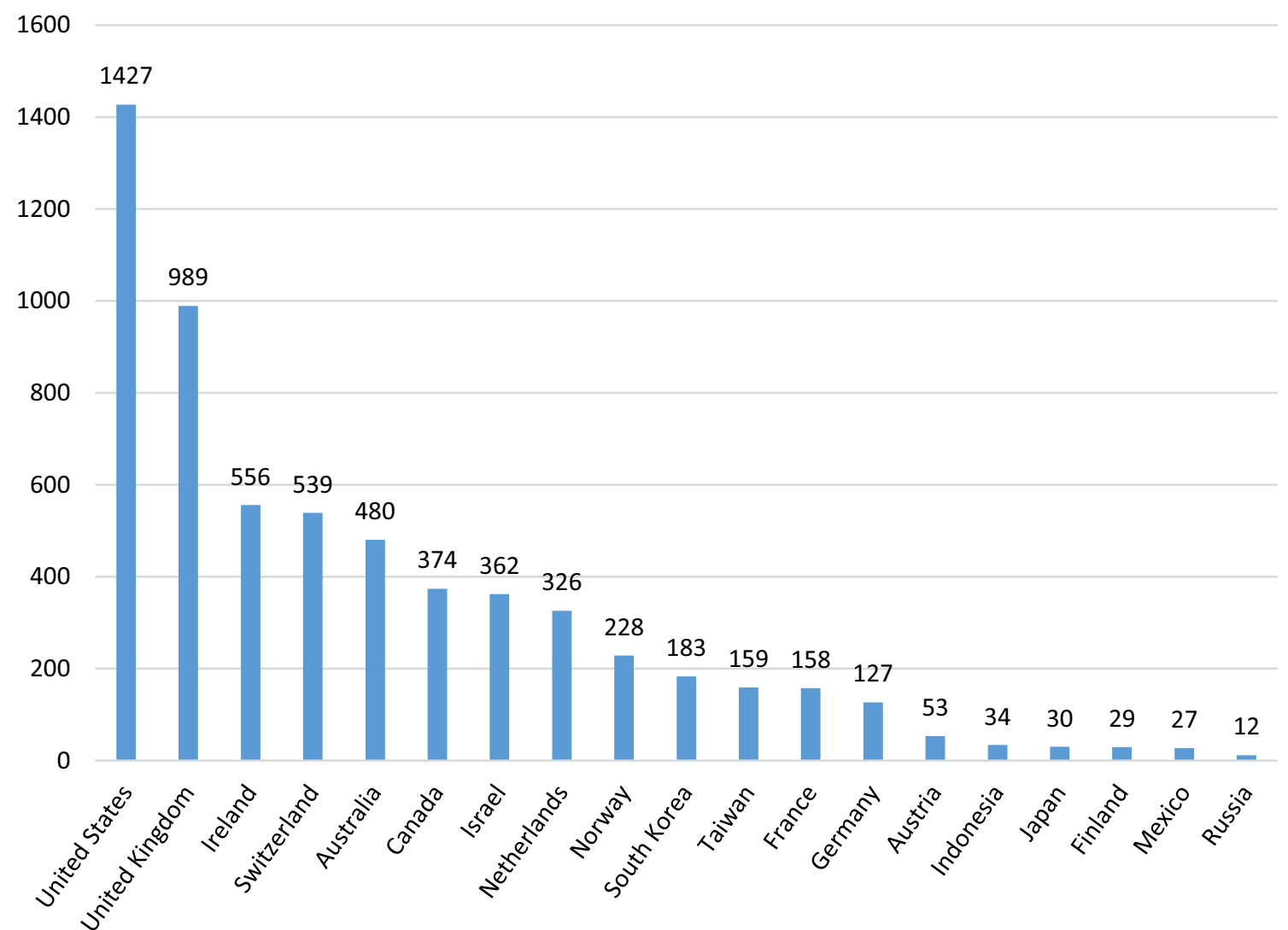

Fig. 1 Average donations in US dollars to charitable causes by people in nineteen countries Source IIPD (2016) Notes The philanthropic donations have been measured in the local currency of each country and have been converted to the value of 2012 US dollars using historical exchange rates (Oanda 2014) and the Consumer Price Index (CPI-U) (US Bureau of Labor Statistics 2014). This figure is similar to Fig. 1 in Wiepking et al. (2020)
Table 1 Percentage of people helping a stranger in the past four weeks-top 10 and bottom 10 countries

\begin{tabular}{llllll}
\hline & Ranking top & Score & & Ranking bottom & Score \\
\hline Liberia & 1 & $77 \%$ & Latvia & 116 & $32 \%$ \\
Sierra Leone & 2 & $74 \%$ & Slovakia & 117 & $32 \%$ \\
USA & 3 & $72 \%$ & Belarus & 118 & $32 \%$ \\
Kenya & 4 & $68 \%$ & China & 119 & $31 \%$ \\
Zambia & 5 & $67 \%$ & Croatia & 120 & $30 \%$ \\
Uganda & 6 & $66 \%$ & Czech republic & 121 & $29 \%$ \\
Nigeria & 7 & $66 \%$ & Madagascar & 122 & $29 \%$ \\
Iraq & 8 & $65 \%$ & Serbia & 123 & $28 \%$ \\
Canada & 9 & $64 \%$ & Cambodia & 124 & $24 \%$ \\
New Zealand & 10 & $64 \%$ & Japan & 125 & $24 \%$ \\
\hline
\end{tabular}

Source Gallup World Poll (GWP 2018) as reported in Charity Aid Foundation World Giving Index (CAF 2019)

helped a stranger in the past four weeks. People in Liberia, Sierra Leone and the USA most often report to have helped a stranger, while people in Serbia, Cambodia and Japan least often report this behavior (CAF 2019; GWP 2018).

While there is apparent evidence that philanthropic behavior and the motivations for this behavior are at least to some extent universal, there is also evidence that people across the world do not equally display these types of behavior. How can we explain these differences in philanthropic behavior worldwide? And, more importantly, what can we learn from this? If research better understands why people differ in the display of philanthropic behaviors across different countries and cultures, it can make important contributions to society: It could support the development of societies where people are more inclined to display philanthropic behaviors and benefit others and the 
public good. ${ }^{1}$ In this article, I will demonstrate that three problems intrinsic to the current study of global philanthropy-geographical orientation, connotations and definitions-are limiting the contribution of our field to society.

In a recent overview of the social bases of philanthropy, Barman (2017) examines the micro-, meso- and macro-level explanations for philanthropy. She defines philanthropy as "private giving for public purposes" (Barman 2017, p. 272). Her conclusion is that in the literature, much knowledge has accumulated about the "characteristics, traits and roles of actors" (micro-level), and the "embeddedness in dynamic and changing social relationships" (meso-level) of philanthropic behavior (Barman 2017, pp. 277-278). However, she concludes that the study of the macro-level, the embeddedness of donors "in broader societal configurations that encourage or constrain charitable giving," is limited and in need of further development (Barman 2017, pp. 280-281).

I echo her call for the development of the macro-level study of philanthropy, as I believe it is the lack of macro-level research in philanthropy that is limiting the contribution of our field to society. We need to better understand, measure and explain the variation in philanthropic behavior in all its forms across geographical units, and only then, we can contribute to evidence-based interventions to stimulate philanthropic behavior leading to improved societal outcomes.

Across the world, governments, corporations and civil society organizations are continuously implementing new policies, rules and regulations which change the context for philanthropic behaviors. These interventions are rarely evaluated. Think for example about the changes in laws that are made each year across countries, for example leading to more restrictive environments for civil society organizations (CIVICUS 2019; IU Lilly Family School of Philanthropy 2018). Consider the many changes in fiscal incentives for giving to charitable organizations (CAF 2016; Dehne et al. 2008). Also relevant here are (fiscal) policies influencing the billions of dollars that are sent home yearly by migrants through remittances, not only to support their own nuclear families, but also their more distant kin and communities (Adelman et al. 2016; Moreno-Dodson et al. 2012; Tertytchnaya et al. 2018). And as a

\footnotetext{
${ }^{1}$ By no means am I calling for an uncritical increase in philanthropic behaviors. Higher levels of philanthropic behaviors, and especially more charitable giving, do not necessary lead to better societal outcomes or may lead to outcomes that are primarily favorable to "ingroups" (e.g., see Balliet et al. 2014). This is well documented in the critiques in Europe (e.g., see Breeze 2019; McGoey 2015) and the USA (Callahan 2017; Reich 2018; Villanueva 2018). I do contend that the overall outcome of philanthropic behavior should lead to improved societal outcomes for everyone, not just for selective groups within society. How we can determine this, who determines this and how we can best study this is another very important and relevant topic of research, beyond the scope of this article.
}

final example consider the blood and organ donation collection regimes that influence donation rates across countries (Gorleer et al. 2020; Healy 2000; Johnson and Goldstein 2003). These are all examples of how the macrolevel, the contextual level, influences individual philanthropic behaviors.

We also know very little about how demographic, economic and social changes influence philanthropic behaviors across geographical contexts (IU Lilly Family School of Philanthropy 2018). It would be of great relevance to also better understand and predict the influence of aging populations, economic downturns, increasing wealth inequality, secularization, technological developments and human-made and natural disasters on philanthropic behavior outside Western Europe and North America, to name a few significant developments at the societal level. ${ }^{2}$

There are good reasons for the underdevelopment of the macro-level study of philanthropy. In the next section of this article, I will set out some of the current barriers and challenges that I contend researchers are facing in the global study of philanthropy, and offer suggestions for solutions to overcome these issues to enable further development of this research field. I contend there are three large problems with the global study of philanthropy: the problem with geographical orientation, the problem with connotations and the problem with definitions.

\section{The Problem with Geographical Orientation}

Figure 2 shows the geographical distribution of articles in the field of nonprofit studies published in 19 academic journals, as shown by Ma and Konrath (Fig. 7 in Ma and Konrath 2018, p. 1146). The darker the color, the more articles originated from that country. Here you can clearly see that most articles originate from North America, Western Europe, Australia and India. While the inclusion of India in the figure from $\mathrm{Ma}$ and Konrath seems encouraging for the representation of countries in nonprofit studies, the statistics for two key journals in our field: Voluntas and the Nonprofit and Voluntary Sector Quarterly (NVSQ), are less hopeful. In 2017, 71\% of the articles published in Voluntas and $84 \%$ of those published in NVSQ originated from either North America or Western Europe. $^{3}$ The lack of geographical representation of

\footnotetext{
${ }^{2}$ Interesting examples exploring some of these topics from various disciplines are Bennett and Einolf (2017), Götz et al. (2020), Ruiter and De Graaf (2006) and Yonah (2019).

${ }^{3}$ Personal communication with editors NVSQ and Voluntas, 2019. Alternative operationalizations of origin of academic articles could include using the geographical focus of the work itself or the source of the data used in empirical papers. I thank one of the anonymous reviewers to this article for this last suggestion.
} 


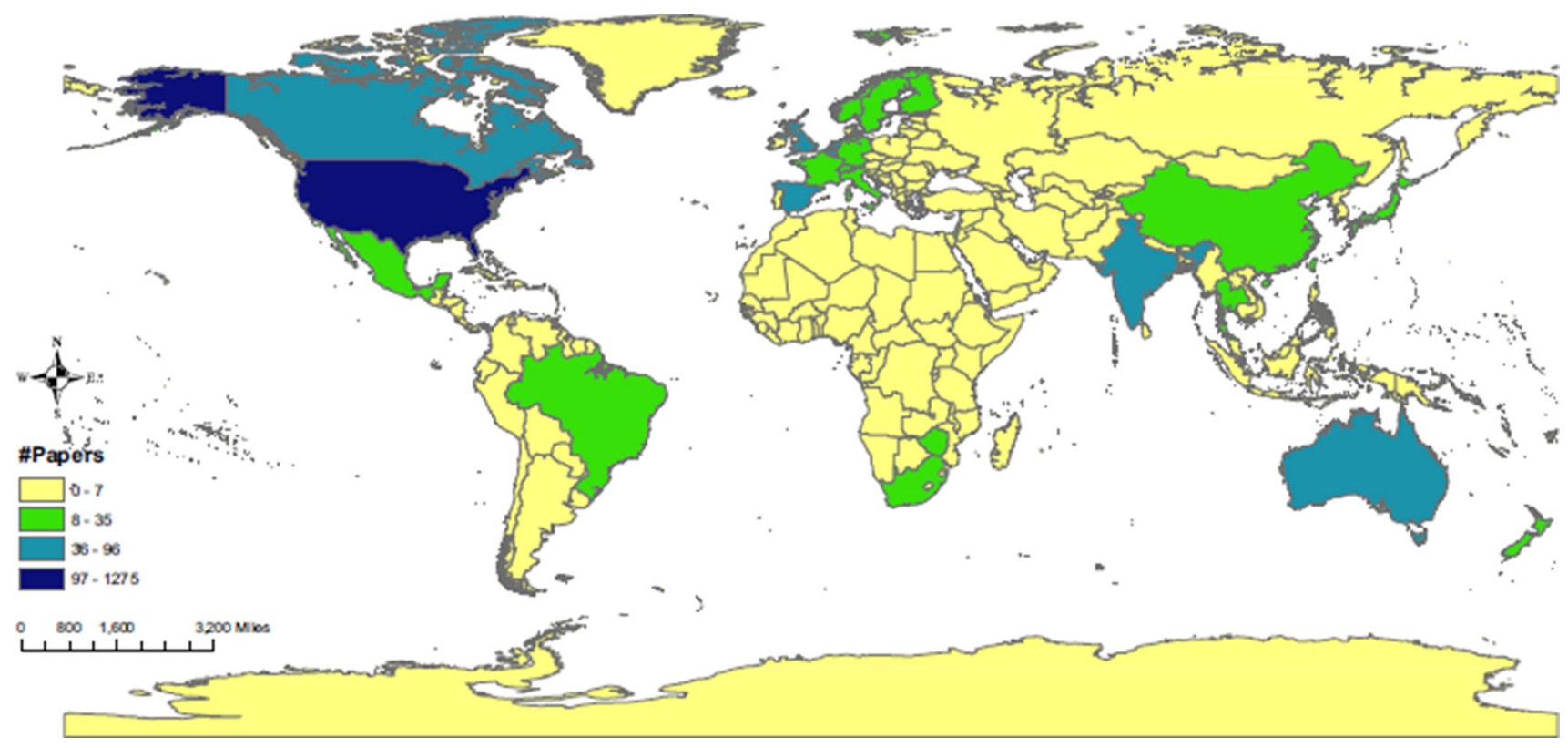

Fig. 2 Geographical representation of publications in nonprofit studies, based on authors' affiliation Source Fig. 7 in Ma and Konrath (2018, p. 1146)

scholarly research on philanthropy is problematic, because this leads to a unidimensional North American or Western European view of what is "philanthropy" and consequently which countries are "more philanthropic." And as a result, research and policy interventions are mostly based on this view.

There are many barriers for scholars studying geographical units outside North America and Western Europe, including lack of geographically diverse representation on editorial boards, lack of reviewers with local geographical and cultural knowledge, different frames and paradigms for academic research and publications, commercial presses and their paywalls, a constant requirement to compare and contrast with the situation in the USA, and the lack of high-quality, valid and reliable quantitative data. ${ }^{4}$ In particular, this last barrier is an important limiting factor for the global study of philanthropy (Bekkers 2016). To collect the high-quality quantitative data needed to publish in academic journals is very difficult and especially costly in contexts outside North America and Western Europe. In addition, there are only a few quantitative data sources that allow for the comparative study of philanthropic behaviors, including the publicly available Eurobarometer (EB 2004), World Values Survey (WVS 2005), European Social Survey (ESS 2003),

\footnotetext{
${ }^{4}$ These are the most important barriers mentioned by the audience and journal editors during the colloquium "Still WEIRD: Increasing the representation of global philanthropy research", at the $48^{\text {th }}$ ARNOVA Conference in San Diego, USA, November 21, 2019. A summary of this colloquium can be found here: https://tinyurl.com/ yb48jt8h.
}

Individual International Philanthropy Database (IIPD 2016) and the costly Gallup World Poll (GWP 2018). All but the GWP and the IIPD rely on data collected almost two decades ago, and only the GWP and the WVS provide a global sample. In addition, there are intrinsic problems with these existing quantitative data sources, which I will elaborate on in the section covering the problem with definitions later in this article.

\section{The Problem with Connotations}

The second problem I want to discuss relates to connotations that people have with the word "philanthropy," which is used in most of the published research. For many people across the world, including Western Europe and North America, philanthropy is associated with "rich, white men giving away their money-and not always for charitable reasons" (Herzog et al. 2020, p. 463). When thinking about philanthropy, for many people images of historical figures such as Carnegie and Rockefeller or more recent philanthropists such as Bill Gates and Warren Buffet come to mind. As women in the video "Who is a philanthropist?" from the Women's Philanthropy Institute fittingly state: "People [philanthropists] are viewed as needing to be rich, multi-billionaires, millionaires, famous people", "Philanthropist' has a connotation of old white men", and "philanthropists [are] rich, wealthy, who are on tv, run an organization, not just a regular person" (Women's Philanthropy Institute 2019). 
Figure 3 shows a painting nicknamed "The Mayor of Delft," a painting by Dutch painter Jan Steen, which to me is one of the most intriguing philanthropy paintings from my country, the Netherlands. You see a burgher, which is a title for an upper class citizen in Jan Steen's time, and his daughter, who in the most careless way give a donation to a poor lady and her son. Why would someone want to be depicted like that? This image is not that of the typical Maecenas. But it is illustrative for how many people see philanthropy and philanthropists, and the connotations they have with these words.

To connect this article with the recent critiques of philanthropy in the USA (Callahan 2017; Giridharadas 2018; Reich 2018; Villanueva 2018) and older critiques of philanthropy in Europe (Lassig 2004; Owen 1965; Rodgers 1949; Rosenthal 1972), there are many issues with that kind of philanthropy. Although, at the same time, there are a great many "Big Philanthropists" out there who do genuinely care for others and are committed to contribute to improved societal outcomes (Breeze 2019; Buchanan 2019).

\section{The Problem with Definitions}

The final and probably most important and complicated problem I want to discuss relates to definitions. The problem with the definition of philanthropy also reflects the problems with geographical orientation and connotations. And although several scholars have made excellent contributions to different cultural-and more inclusive-

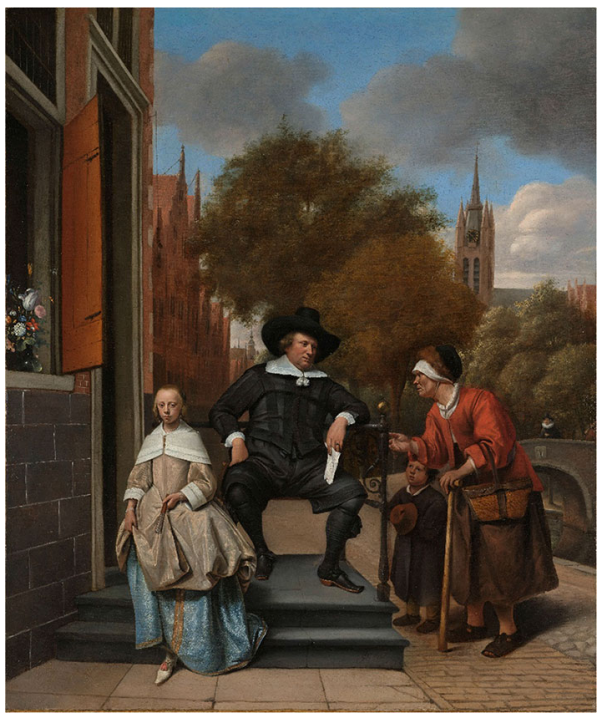

Fig. 3 Adolf en Catharina Croeser aan de Oude Delft, Jan Steen (1655). Location: Rijksmuseum Amsterdam, the Netherlands definitions of philanthropy, including Salamon and Anheier (1992, 1998), Payton and Moody (Payton 1988; Payton and Moody 2008), Sulek (2010a, b), Butcher and Einolf (2017), Campbell and Çarkoğlu (2019), Bies and Kennedy (2019), Fowler and Mati (2019) and Schuyt (2020), I believe much more global research is needed to inform a truly inclusive and comprehensive discussion of the global definition of philanthropy and of how different disciplines have coined this term in different national, cultural or language contexts. Fowler and Mati put the problem with definitions really well: "[...] from a global perspective, comprehension of philanthropy is biased and incomplete, calling for a more open understanding of the phenomena" (Fowler and Mati 2019, p. 724). To solve the issue with a global definition of philanthropy, I argue we first need to conduct large-scale comparative qualitative research into the conceptualization, meaning and understanding of philanthropy on a global scale. At the end of this article, I will share strategies for how I believe scholars can contribute to this.

In the meanwhile, because of the unidimensional North American and Western European view in the literature of what "philanthropy" is, philanthropy is typically defined in line with Payton, as "voluntary action for the public good" (Payton 1988, p. 7). And it is often operationalized as formal philanthropic giving, financial donations to charitable organizations. This is exactly what is done in one of the few existing datasets available for the comparative study of philanthropic behavior, the Individual International Philanthropy Database (IIPD 2016). The IIPD was created through the merge and synchronization of existing representative micro-level surveys. Researchers voluntarily contributed their data to create a comparative database including the incidence and amount people donated to charitable organizations in nineteen countries (Wiepking and Handy 2016). As such, it is the first, and so far only, comparative data that include the amounts of money that people give to charities, which is of high relevance when studying how the macro-level context relates to individuallevel philanthropic behavior (see for analyses using the IIPD De Wit et al. 2018; Wiepking et al. 2020). However, as I mentioned, there are intrinsic problems with existing datasets like the IIPD. The first and foremost problem is the operationalization of philanthropic behavior only as formal philanthropic giving: monetary donations to charitable organizations. This behavior is largely dependent on the opportunity to give to formal charitable organizations, which is related to-among others - the local institutionalization of these organizations, and the trust people have in them (Campbell and Çarkoğlu 2019; Fowler and Mati 2019; Wiepking and Handy 2015a; Yasin 2020). In addition, the IIPD only covers a selective range of countries, predominantly in Western Europe, North America and 
Asia, and the data have been collected using different methodologies across different time frames. ${ }^{5}$

In addition to the IIPD, the Gallup World Poll (GWP 2018) also illustrates the intrinsic problems with existing comparative data sources. Like the IIPD, the GWP uses limited definitions and consequently problematic operationalizations of philanthropic behavior. In the GWP, between 2009 and 2018 representative samples of between 120 and 150 countries in the world were asked the following three questions annually:

Have you done any of the following in the past month?

- Helped a stranger, or someone you didn't know who needed help?

- Donated money to a charity?

- Volunteered your time to an organization?

There are several issues with using these questions as a proxy for philanthropic behavior. These issues relate to the already mentioned cultural differences in definitions and differences in the opportunity of displaying these three behaviors, but also to language barriers; cultural differences in reporting of these behaviors; and the use of different time periods of reporting in the GWP, including local and religious holidays that correspond with higher giving, volunteering and helping. It is quite problematic that the Charitable Aid Foundation (CAF) uses aggregated data from the GWP to compare and rank countries in terms of "their generosity" in their World Giving Index (CAF 2019). It is no coincidence that the top 10 highest ranking countries consistently include predominantly English language countries. This is illustrated in Table 2 with the overall ranking of countries in the CAF Giving Index over the past ten years (CAF 2019).

I believe it is very problematic to create rankings of "most generous countries," especially given the limitations in the operationalization of philanthropy in the GWP. It is a rather excluding practice: What do people living in countries ranking at the bottom think about this? From research, we know that people in those countries also display a wide range of generosity behaviors, as is illustrated for example by work on Bulgaria (Bieri and Valev 2015), Russia (Mersianova et al. 2015), Serbia (Radovanovic 2019) and China (Xinsong et al. 2015), countries that all rank in the bottom ten places in the 2019 CAF World Giving Index. Research shows that people in those countries are also generous, but in ways that are not captured by these rather unidimensional measures developed for WEIRD populations (Henrich et al. 2010). In which WEIRD stands for Western, higher Educated, Industrialized, Rich and Democratic.

\footnotetext{
5 See Wiepking et al. (2020) for a more complete discussion of the methodological issues related to the IIPD.
}

There are many other ways people can display behavior that is beneficial to others: They can volunteer for organizations, donate organs, blood or other body fluids or in more informal ways help others, both kin and non-kin, care for others and share their resources, including expertise. In order to study global philanthropy, we need to understand the different concepts, meanings, definitions and motivations that people across the world have in relation to this phenomenon, continuing the work by-among othersSalamon and Anheier (1992, 1998), Fowler and Mati (2019) and Campbell and Çarkoğlu (2019). ${ }^{6}$ As a personal critique, my own research has suffered from similar biases. I have conducted mostly research on "formal philanthropy," using Western European perspectives and definitions, and studying WEIRD populations. In my future research, I intend to take into account all forms of philanthropy, using local words and definitions, and study the world's population. In the final section of this article, I am suggesting the first steps for a collaborative research agenda, inspired to come to a truly global and inclusive understanding of philanthropic behavior. Interested researchers are explicitly encouraged to seek collaboration and help develop this agenda.

\section{A Future Collaborative Research Agenda: To Come to An Inclusive Study of Global Philanthropy}

The first step to overcome barriers and challenges that researchers are facing in the global study of philanthropy is to start by tackling the problems with connotations. One tentative suggestion is to replace the use of the word "philanthropy" with "generosity," when studying this phenomenon globally. I say tentatively, because I fully realize there may not be one global term for this complex, multifaceted behavior. But, in contrast to philanthropy, generosity appears to have a more favorable connotation. In a series of informational interviews with scholars and practitioners from across the world, Herzog et al. (2020) conclude that generosity "is seen to be a softer concept, one that is more concerned with the motivation or values behind the act of giving than with the gift itself." (Herzog et al. 2020, p. 464). In lieu of better-unified terminology, I will use "generosity" moving forward, until research presents us with better alternatives.

\footnotetext{
${ }^{6}$ Philanthropy infrastructure organizations are also contributing extensively to increased understanding of philanthropy from a global perspective, for example through whitepapers (Hartnell 2017, 2018a, b, 2019, 2020; Hartnell and Milner 2018) and reports (see, for example, EU Russia Civil Society Forum 2017; WINGS 2018).
} 
Table 2 The world's highest ranking countries in the $\mathrm{CAF}$ Giving Index-10-year trends

\begin{tabular}{|c|c|c|c|c|c|c|c|c|}
\hline & \multicolumn{2}{|l|}{ Overall } & \multicolumn{2}{|l|}{ Helping } & \multicolumn{2}{|c|}{ Giving money } & \multicolumn{2}{|c|}{ Volunteering } \\
\hline & Ranking & $\%$ & Ranking & $\%$ & Ranking & Score & Ranking & $\%$ \\
\hline USA & 1 & $58 \%$ & 3 & $72 \%$ & 11 & $61 \%$ & 5 & $42 \%$ \\
\hline Myanmar & 2 & $58 \%$ & 49 & $49 \%$ & 1 & $81 \%$ & 3 & $43 \%$ \\
\hline New Zealand & 3 & $57 \%$ & 10 & $64 \%$ & 9 & $65 \%$ & 6 & $41 \%$ \\
\hline Australia & 4 & $56 \%$ & 11 & $64 \%$ & 8 & $68 \%$ & 12 & $37 \%$ \\
\hline Ireland & 5 & $56 \%$ & 16 & $62 \%$ & 7 & $69 \%$ & 10 & $38 \%$ \\
\hline Canada & 6 & $55 \%$ & 9 & $64 \%$ & 10 & $63 \%$ & 11 & $37 \%$ \\
\hline UK & 7 & $54 \%$ & 19 & $60 \%$ & 2 & $71 \%$ & 25 & $30 \%$ \\
\hline Netherlands & 8 & $53 \%$ & 37 & $53 \%$ & 5 & $71 \%$ & 14 & $36 \%$ \\
\hline Sri Lanka & 9 & $51 \%$ & 29 & $55 \%$ & 19 & $50 \%$ & 1 & $46 \%$ \\
\hline Indonesia & 10 & $50 \%$ & 86 & $42 \%$ & 6 & $69 \%$ & 7 & $40 \%$ \\
\hline
\end{tabular}

Source Gallup World Poll (2018) as reported in Charity Aid Foundation World Giving Index (CAF 2019)
Secondly, we need to work on the problems with definitions. We know that people across the globe practice different types of generosity behaviors. In order to come to an inclusive understanding of what types of generosity behavior people across the world practice, the language they use to discuss this, the motivations they have for this behavior, and not less important, how we can ask them to report about this, we can use several strategies. I highlight two complementary strategies. The first is to continue the excellent qualitative work into all forms of generosity behavior that researchers have been and are continuing to conduct locally, to mention a few examples, in addition to the already mentioned studies by Butcher and Einolf (2017), Fowler and Mati (2019), Campbell and Çarkoğlu (2019) and Bies and Kennedy (2019): a study of the role of the state in relation to volunteering in China ( $\mathrm{Hu} 2020)$; different types of prosocial behavior in Brazil (Vieites 2017); charitable giving to health care in Iran (Ziloochi et al. 2019); the motivations of international volunteers from Japan (Okabe et al. 2019); employee volunteering in Iran (Afkhami et al. 2019); and individual giving in India (Sen et al. 2020), China (Yang and Wiepking 2020), Ethiopia (Yasin 2020) and Mexico (Butcher García-Colín and Ruz 2016). A second strategy I like to suggest is a large-scale, comparative, qualitative study, where local and international researchers and students interview representative citizens about their "generosity" behaviors and motivations for this behavior in their own language. ${ }^{7}$

\footnotetext{
${ }^{7}$ We are building a research community of scholars interested to contribute to the global and inclusive understanding of generosity behavior and the motivations for this behavior, using open science practices. At the OSF site for this project (https://osf.io/y9cju/), you can find, for example, interview protocols developed by the author and Kidist Yasin and Anastesia Okaomee, graduate students at the IU Lilly Family School of Philanthropy. We are continuously adding deidentified interview transcripts using these protocols for anyone to use in their research. Any scholar or student interested to join our
}

Only when we have a better qualitative understanding of the language, meaning, practices and motivations of generosity behaviors across the world, we may be able to design a quantitative study where we comparatively operationalize and measure these behaviors and their motivations. This quantitative study would need to incorporate the multifaceted definitions of generosity and use local languages and terminology in order to be inclusive of the different behaviors and motivations. When these data are collected using open science practices, researchers from across the world would have access to high-quality databoth qualitative and quantitative-measuring generosity behaviors. This will likely increase the geographical representation of published academic research on generosity, the remaining problem addressed in this article.

A final suggestion for a research agenda for the global study of generosity targets solving the lack of comparable information on the institutionalization, policies, rules and regulations that make up the context for generosity behaviors. In order to conduct macro-level comparative research, high-quality country- and regional-level data are necessary. A start to collect these contextual data was made in the project that resulted in the IIPD (2016) and the Palgrave Handbook of Global Philanthropy (Wiepking and Handy 2015b): the Contextual International Philanthropy Database (CIPD work in progress). ${ }^{8}$

Here, collaboration with governments, civil society actors and especially international civil society network organizations such as WINGS and CIVICUS may be very relevant. Only when high-quality data about the changing

\section{Footnote 7 continued}

community is welcome to join, please contact the author using the contact details provided with this article.

${ }^{8}$ The Contextual International Philanthropy Database (CIPD work in progress), including an editable version, is publicly available through a link at the OSF site related to this project: (https://osf.io/y9cju/). 
(institutional) context for generosity behavior are available, researchers will be able to study the implications of interventions intended to stimulate global generosity. And only then, they will be able to contribute to development of societies where people are more inclined to display generosity behaviors with the aim to contribute to improved societal outcomes for everyone.

Acknowledgements I would like to thank the audience of the 2019 ERNOP Conference in Basel, Switzerland, the three anonymous reviewers, the editors of this special issue and René Bekkers and Femida Handy for their feedback to previous versions of this work. I am thankful for Beth Breeze for the generous sharing of resources on European critiques of philanthropy as well as her feedback to a previous version of this article. The author would also like to thank the many students who have contributed to this article in one way or another: first of all, $\mathrm{PhD}$ students Kidist Yasin, Yongzheng Yang, Dana Doan and Anastesia Okaomee who have shared many insights and through this helped me develop new thoughts and ideas about studying generosity from a non-WEIRD perspective, but also all my students in the global philanthropy classes at the IU Lilly Family School of Philanthropy, who shared their experience and insights related to the practice of global philanthropy, and interviewed people all across the global on their generosity behaviors. Finally, I am thankful for the support for my work by Mary-Joy and Jerre Stead, their family and the Dutch Charity Lotteries.

Funding The work by Pamala Wiepking at the Lilly Family School of Philanthropy is funded through a donation by the Stead Family, and her work at the Vrije Universiteit Amsterdam is funded by the Dutch Charity Lotteries.

\section{Compliance with Ethical Standards}

Conflict of interest The author declares that she has no conflict of interest.

Open Access This article is licensed under a Creative Commons Attribution 4.0 International License, which permits use, sharing, adaptation, distribution and reproduction in any medium or format, as long as you give appropriate credit to the original author(s) and the source, provide a link to the Creative Commons licence, and indicate if changes were made. The images or other third party material in this article are included in the article's Creative Commons licence, unless indicated otherwise in a credit line to the material. If material is not included in the article's Creative Commons licence and your intended use is not permitted by statutory regulation or exceeds the permitted use, you will need to obtain permission directly from the copyright holder. To view a copy of this licence, visit http://creativecommons. org/licenses/by/4.0/.

\section{References}

Adelman, C., Barnett, J. N., \& Riskin, E. (2016). Index of global philanthropy and remittances. Washington, DC: Hudson Institute.

Afkhami, A., Nasr Isfahani, A., Abzari, M., \& Teimouri, H. (2019). Toward a deep insight into employee participation in employersupported volunteering in Iranian organizations: A grounded theory. VOLUNTAS: International Journal of Voluntary and Nonprofit Organizations, 30(5), 1036-1053.
Aknin, L. B., Barrington-Leigh, C. P., Dunn, E. W., Helliwell, J. F., Burns, J., Biswas-Diener, R., et al. (2013). Prosocial spending and well-being: Cross-cultural evidence for a psychological universal. Journal of Personality and Social Psychology, 104(4), 635-652.

Balliet, D., Wu, J., \& De Dreu, C. K. (2014). Ingroup favoritism in cooperation: A meta-analysis. Psychological Bulletin, 140(6), $1556-1581$.

Barman, E. (2017). The social bases of philanthropy. Annual Review of Sociology, 43, 271-290.

Bekkers, R. (2016). The Analysis of Regional Differences in Philanthropy: Evidence from the European Social Survey, the Eurobarometer and the Giving in the Netherlands Panel Survey. In R. Meuleman, G. Kraaykamp, \& M. Wittenberg (Eds.), Nederland in context: verschillen en overeenkomsten (pp. 26-49). Den Haag, the Netherlands: DANS.

Bennett, M. R., \& Einolf, C. J. (2017). Religion, altruism, and helping strangers: A multilevel analysis of 126 countries. Journal for the Scientific Study of Religion, 56(2), 323-341.

Bieri, F., \& Valev, N. T. (2015). Giving in Bulgaria: A nonprofit sector in transition. In P. Wiepking \& F. Handy (Eds.), The Palgrave handbook of global philanthropy (pp. 118-136). Hampshire: Palgrave MacMillan.

Bies, A., \& Kennedy, S. (2019). The state and the state of the art on philanthropy in China. VOLUNTAS: International Journal of Voluntary and Nonprofit Organizations, 30(4), 619-633.

Borgonovi, F. (2008). Divided we stand, united we fall: Religious pluralism, giving, and volunteering. American Sociological Review, 73(1), 105-128.

Breeze, B. (2019). Philanthropy's bad reputation could put big donors off giving - here's why it matters. The Conversation U.K. https:// theconversation.com/philanthropys-bad-reputation-could-putbig-donors-off-giving-heres-why-it-matters-116023. Accessed 11 Dec 2019.

Buchanan, P. (2019). Giving done right: Effective philanthropy and making every dollar count. New York: Public Affairs.

Butcher, J., \& Einolf, C. J. (2017). Perspectives on volunteering. Cham: Springer.

Butcher García-Colín, J., \& Ruz, S. S. (2016). Giving Mexico: Giving by individuals. VOLUNTAS:International Journal of Voluntary and Nonprofit Organizations, 27(1), 322-347.

CAF. (2016). Donation states. An international comparison of the tax treatment of donations. London, U.K.: Charities Aid Foundation. https://www.cafonline.org/docs/default-source/about-us-publica tions/fwg4-donation-states. Accessed 11 Dec 2019.

CAF. (2019). CAF World giving index. Ten years of giving trends. London, UK: Charities Aid Foundation. https://www.cafonline. org/about-us/publications/2019-publications/caf-world-givingindex-10th-edition. Accessed 11 Dec 2019.

Callahan, D. (2017). The givers: Wealth, power, and philanthropy in a new gilded age. New York: Vintage Books.

Campbell, D. A., \& Çarkoğlu, A. (2019). Informal giving in Turkey. VOLUNTAS: International Journal of Voluntary and Nonprofit Organizations, 30(4), 738-753.

CIVICUS. (2019). State of civil society report 2019. Johannesburg, South Africa: CIVICUS. https://www.civicus.org/index.php/ state-of-civil-society-report-2019. Accessed 3 Dec 2019.

Cutler, J., \& Campbell-Meiklejohn, D. (2019). A comparative fMRI meta-analysis of altruistic and strategic decisions to give. NeuroImage, 184, 227-241.

De Wit, A., Neumayr, M., Handy, F., \& Wiepking, P. (2018). Do government expenditures shift private philanthropic donations to particular fields of welfare? evidence from cross-country data. European Sociological Review, 34(1), 6-21. 
Dehne, A., Friedrich, P., Nam, C. W., \& Parsche, R. (2008). Taxation of nonprofit associations in an international comparison. Nonprofit and Voluntary Sector Quarterly, 37(4), 709-729.

ESS. (2003). European Social Survey, wave I. [computer file] Bergen, Norway: Norwegian Social Science Data Services (NSD).

EU Russia Civil Society Forum. (2017). 2016 Report on the state of civil society in the EU and Russia. Berlin: EU Russia Civil Society Forum.

Eurobarometer. (2004). Eurobarometer 62.2 Agricultural Policy, Development Aid, Social Capital, and Information and Communication Technology. [computer file]. Köln: European Commission, Directorate General Press and Communication, Opinion Polls.

Fowler, A., and Mati, J. M. (2019). African Gifting: Pluralising the Concept of Philanthropy. VOLUNTAS: International Journal of Voluntary and Nonprofit Organizations, 30, 724-737.

Giridharadas, A. (2018). Winners take all: The elite charade of changing the world. New York: Vintage Books.

Gorleer, S., Bracke, P., \& Hustinx, L. (2020). The organizational field of blood collection: A multilevel analysis of organizational determinants of blood donation in Europe. European Sociological Review, 36(3), 474-492.

Götz, N., Brewis, G., \& Werther, S. (2020). Humanitarianism in the modern world: The moral economy of famine relief. Cambridge: Cambridge University Press.

GWP. (2018). The Gallup World Poll. Washington: Gallup. https:// www.gallup.com/analytics/232838/world-poll.aspx. Accessed 3 Aug 2020.

Hartnell, C. (2017). Philanthropy in India. A Working paper. Philanthropy for social justice and peace in association with Alliance, WINGS and the Centre for Social Impact and Philanthropy, Ashoka University. http://www.psjp.org/the-roleof-philanthropy-in-society-2/. Accessed 3 Aug 2020.

Hartnell, C. (2018a). Philanthropy in Russia. A Working paper. Philanthropy for Social Justice and Peace in association with Alliance, WINGS and Philanthropy Network for Social Justice. http://www.psjp.org/the-role-of-philanthropy-in-society-2/. Accessed 3 Aug 2020.

Hartnell, C. (2018b). Philanthropy in the Arab Region. A Working paper. Philanthropy for Social Justice and Peace in association with Alliance, Arab Foundations Forum, John D Gerhart Center for Philanthropy, King Khalid Foundation, Philanthropy Age, SAANED and WINGS. http://www.psjp.org/the-role-of-philan thropy-in-society-2/. Accessed 3 Aug 2020.

Hartnell, C. (2019). Individual giving in India, Russia, the Arab region and Brazil. PSJP in association with Alliance, CAF Russia, Philanthropy Network for Social Justice (Rede de Filantropia Para a Justica Social), Institute for the Development of Social Investment (IDIS), SAANED and WINGS. http:// www.psjp.org/the-role-of-philanthropy-in-society-2/. Accessed 3 Aug 2020.

Hartnell, C. (2020). Philanthropy in Indonesia. A Working paper. Philanthropy for Social Justice and Peace in association with Alliance, Filantropi Indonesia, Indonesia for Humanity and WINGS. http://www.psjp.org/the-role-of-philanthropy-insociety-2/. Accessed 3 Aug 2020.

Hartnell, C., and Milner, A. (2018). Philanthropy in Brazil. A Working paper. Philanthropy for Social Justice and Peace in association with Alliance, WINGS and Philanthropy Network for Social Justice. Accessed 3 Aug 2020.

Healy, K. (2000). Embedded altruism: Blood collection regimes and the European Union's donor population. American Journal of Sociology, 105(6), 1633-1657.

Henrich, J., Boyd, R., Bowles, S., Fehr, E., Camerer, C., \& Gintis, H. (2004). Foundations of human sociality: Economic experiments and ethnographic evidence from fifteen small-scale societies. Oxford: Oxford University Press on Demand.

Henrich, J., Heine, S. J., \& Norenzayan, A. (2010). Most people are not WEIRD. Nature, 466(7302), 29.

Herzog, P. S., Strohmeier, A., King, D. P., Khader, R., Williams, A. L., Goodwin, J. L., et al. (2020). Religiosity and generosity: Multi-level approaches to studying the religiousness of prosocial actions. Religions, 11, 446. https://doi.org/10.3390/rel11090446.

$\mathrm{Hu}$, M. (2020). Making the state's volunteers in contemporary China. VOLUNTAS: International Journal of Voluntary and Nonprofit Organizations. https://doi.org/10.1007/s11266-019-00190-9.

IIPD. (2016). Individual International Philanthropy Database, version 1. [computer file]. Wiepking, P. and Handy, F. [principle investigators]. Rotterdam: Erasmus University Rotterdam [distributor].

IU Lilly Family School of Philanthropy. (2018). 2018 Global philanthropy environment index. Indianapolis: IU Lilly Family School of Philanthropy.

Johnson, E. J., \& Goldstein, D. (2003). Medicine. Do defaults save lives? Science, 302(5649), 1338-1339.

Lassig, S. (2004). Burgerlichkeit, Patronage and Communal Liberalism in Germany 1871-1914. In T. Adams (Ed.), Philanthropy, patronage and civil society: Experiences from Germany, Great Britain and North America. Bloomington: Indiana University Press.

Ma, J., \& Konrath, S. (2018). A century of nonprofit studies: Scaling the knowledge of the field. VOLUNTAS: International Journal of Voluntary and Nonprofit Organizations, 29(6), 1139-1158.

McGoey, L. (2015). No such thing as a free gift: The Gates Foundation and the price of philanthropy. London: Verso Books.

Mersianova, I., Jakobson, L., \& Krasnopolskaya, I. (2015). Giving in Russia: The difficult shaping of the new nonprofit regime. In P. Wiepking \& F. Handy (Eds.), The Palgrave handbook of global philanthropy (pp. 249-266). Hampshire: Palgrave MacMillan.

Moreno-Dodson, B., Mohapatra, S., and Ratha, D. (2012). Migration, Taxation, and Inequality. The World Bank Economic Premise No 80.

Oanda. (2014). Historical Currency Converter. https://www.oanda. com/fx-for-business/historical-rates. Accessed 1 Aug 2018.

Okabe, Y., Shiratori, S., \& Suda, K. (2019). What motivates Japan's international volunteers? categorizing Japan overseas cooperation volunteers (JOCVs). VOLUNTAS: International Journal of Voluntary and Nonprofit Organizations, 30(5), 1069-1089.

Owen, D. (1965). English philanthropy 1660-1960. London: Oxford University Press.

Payton, R. L. (1988). Philanthropy: Voluntary action for the public good. New York: Macmillan Publishing Company.

Payton, R. L., \& Moody, M. P. (2008). Understanding philanthropy : Its meaning and mission. Bloomington: Indiana University Press.

Radovanovic, B. (2019). Individual giving: theoretical discussions and the evidence from Serbia and Canada: ethical issues, contextual and individual factors of giving time and money to organisations and people ( $\mathrm{PhD}$ Thesis). Cambridge, U.K.: University of Cambridge.

Reich, R. (2018). Just giving: Why philanthropy is failing democracy and how it can do better. Princeton: Princeton University Press.

Rodgers, B. (1949). Cloak of charity: Studies in eighteenth-century philanthropy. London: Methuen and Co Ltd.

Rosenthal, J. T. (1972). The purchase of paradise: Gift giving and the aristocracy 1307-1485. London: Routledge and Kegan Paul.

Ruiter, S., \& De Graaf, N. D. (2006). National context, religiosity and volunteering: Results from 53 countries. American Sociological Review, 71(2), 191-210.

Salamon, L. M., \& Anheier, H. K. (1992). In search of the nonprofit sector. I: The question of definitions. VOLUNTAS: International 
Journal of Voluntary and Nonprofit Organizations, 3(2), $125-151$

Salamon, L. M., \& Anheier, H. K. (1998). Social origins of civil society: Explaining the nonprofit sector cross-nationally. VOLUNTAS: International Journal of Voluntary and Nonprofit Organizations, 9(3), 213-248.

Schuyt, T. N. M. (2020). A World of Giving. Philanthropy as a Universal Social Arrangement. Amsterdam, the Netherlands: Draft Manuscript July 2020.

Sen, A., Chatterjee, R. S., Nayak, N. C., \& Mahakud, J. (2020). Determinants of Individual Giving Behavior in Urban India. VOLUNTAS: International Journal of Voluntary and Nonprofit Organizations, 31(2), 271-285.

Sulek, M. (2010a). On the classical meaning of philanthrôpía. Nonprofit and Voluntary Sector Quarterly, 39(3), 385-408.

Sulek, M. (2010b). On the modern meaning of philanthropy. Nonprofit and Voluntary Sector Quarterly, 39(2), 193-212.

Tertytchnaya, K., De Vries, C. E., Solaz, H., \& Doyle, D. (2018). When the money stops: Fluctuations in financial remittances and incumbent approval in central Eastern Europe, the Caucasus and Central Asia. American Political Science Review, 112(4), 758-774.

Thielmann, I., Spadaro, G., \& Balliet, D. (2020). Personality and prosocial behavior: A theoretical framework and meta-analysis. Psychological Bulletin, 146(1), 30-90.

U. S. Bureau of Labor Statistics. (2014). Archived Consumer Price Index Detailed Reports. https://www.bls.gov/cpi/tables/detailedreports/home.htm. Accessed 1 Aug 2018.

Vieites, Y. (2017). The Prosocial class: how social class influences prosocial behavior. Rio de Janeiro, Brasil: Doctoral dissertation Escola Brasileira de Administracao Publica e de Empresas.

Villanueva, E. (2018). Decolonizing wealth: Indigenous wisdom to heal divides and restore balance. Oakland: Berrett-Koehler Publishers.

Wiepking, P., \& Handy, F. (2015a). The practice of philanthropy: The facilitating factors from a cross-national perspective. In $\mathrm{P}$. Wiepking \& F. Handy (Eds.), The Palgrave handbook of global philanthropy (pp. 597-623). Hampshire: Palgrave MacMillan.

Wiepking, P., \& Handy, F. (Eds.). (2015b). The Palgrave handbook of global philanthropy. Hampshire: Palgrave MacMillan.

Wiepking, P., and Handy, F. (2016). Documentation individual international philanthropy database (IIPD). A comparative study of global giving. Rotterdam, the Netherlands: Erasmus University Rotterdam.
Wiepking, P., Handy, F., Park, S., Neumayr, M., Bekkers, R., Breeze, B., et al. (2020). Global philanthropy: How institutional factors enable philanthropic giving. Revise and Resubmit with Nonprofit and Voluntary Sector Quarterly.

WINGS. (2018). The global landscape of philanthropy. Sao Paulo: WINGS.

Women's Philanthropy Institute. (2019). Who is a Philanthropist? Indianapolis, IN. https://philanthropy.iupui.edu/institutes/ womens-philanthropy-institute/research/women-give19-video. html. Accessed 8 July 2020.

World Values Study Group. (2005). World values survey 2005-2006. [computer file] Ann Arbour, MI: Inter-university Consortium for Political and Social Research.

Xinsong, W., Fengqin, L., Fang, N., Xiaoping, Z., \& Xiulan, Z. (2015). Giving in China: An emerging nonprofit sector embedded within a strong state. In P. Wiepking \& F. Handy (Eds.), The Palgrave handbook of global philanthropy (pp. 354-368). Hampshire: Palgrave Macmillan.

CIPD. (work in progress). Contextual International Philanthropy Database. [machine-readable data file]. Wiepking, P. and Handy, F. [principle investigators]. Indianapolis, IN: Lilly Family School of Philanthropy, Indiana University [distributor].

Yang, Y., and Wiepking, P. (2020). Party membership and charitable giving in China: The mediating role of resources, networks, prosocial values, and making compulsory donations. Accepted for publication in Voluntary Sector Review.

Yasin, K. (2020). Philanthropy in Ethiopia: A strong culture of philanthropy amid challenging but improving legal and fiscal infrastructure to the third sector. Indianapolis, IN: Working paper Lilly Family School of Philanthropy.

Yonah, H. (2019). Major life changing events and prosocial behavior. Terrorism, mass shootings, natural disasters, immigration and philanthropy. Jerusalem, Israel: Doctoral Dissertation Hebrew University of Jerusalem.

Ziloochi, M. H., Sari, A. A., Takian, A., \& Arab, M. (2019). Charitable contribution in healthcare: What drives Iranians to donate money? Archives of Iranian Medicine (AIM), 22(3), $109-115$.

Publisher's Note Springer Nature remains neutral with regard to jurisdictional claims in published maps and institutional affiliations. 